\title{
Evaluation of Beliefs and Attitudes of Child Labor Caregivers About Mental Disorders First Aid and Stigma
}

\section{Laleh Ghadirian}

Tehran University of Medical Sciences https://orcid.org/0000-0002-7328-5540

Azadeh Sayarifard ( $\nabla$ drsayarifard@gmail.com )

Knowledge Utilization Research Center, Tehran University of Medical Sciences https://orcid.org/00000002-5510-7177

Research article

Keywords: Belief, Attitude, Child labor, Caregiver, Mental health first aid, Stigma

Posted Date: April 5th, 2021

DOl: https://doi.org/10.21203/rs.3.rs-347060/v1

License: (c) (i) This work is licensed under a Creative Commons Attribution 4.0 International License.

Read Full License 


\section{Abstract}

Background: The beliefs and attitudes of caregivers of working children about mental health issues and first aid, as well as their attitudes about the stigma of mental health problems can affect their motivation seek professional help for affected children. The aim of this study was to assess the mental health literacy of child labor caregivers about first aid for mental health and their attitudes about stigma of mental disorders.

Methods: In this cross-sectional study, the questionnaire was the Depression Health Literacy Questionnaire. All caregivers of working children covered by a NGO in the 17th district of Tehran who wanted to participate were included in the study.

Results: Questionnaires of 129 caregivers were analyzed. Their mean age was $32.6( \pm 7)$ years. Of which $128(99.2 \%)$ were women. Only 37 people (30.3\%) were confident in their ability to help their children in case of depressive symptoms. The majority 109 (84.5\%) of participants believed that asking a depressed child about suicidal ideation was harmful.

Conclusion: According to the findings of this study, the literacy of child labor caregivers about mental health first aid is not enough and there is need to conduct interventions including providing the necessary trainings in this area.

\section{Introduction}

According to the International Labor Organization (ILO) statistics, there are currently 218 million children aged 5 to 17 years are employed worldwide and 73 million of whom are in high-risk forms of child labor (1). Statistics also show that child labor make up about $22 \%$ of the workforce in Asia, $32 \%$ in Africa, $17 \%$ in Latin America and 1\% in the United States, Canada, Europe and other developed countries (2). These findings are shocking, not only because child labor is a debatable violation of children's basic rights, but also because of its potential harm to the educational, physiological and mental development of them (3). Different countries have conducted a number of studies to assess work-related injuries, common illnesses of street children and their psychological injuries, including depression and it is also an urgent need for further research to improve their mental health (4).

Mental health literacy among people of any society shows their knowledge about mental disorders and their understanding of need to visit a specialist in order to receive necessary treatment. So, an important step in promoting mental health of a community is to recognize the state of mental health literacy and need assessment for it, and if necessary, focus on improving it (5).

One of the solutions for promoting mental health literacy is mental health first aid (MHFA) education that is defined as "helping a person who has a mental health problem or is in a mental health crisis" (6-12). Mental health first aid is consisted of providing support and care so that there is no harassment and interference; identifying needs and concerns; listen to the person without judging; helping people access 
to information; social services and support and individual protection against more harm. Mental health first aid is not professional counseling, but is substitute for psychological information that has been found ineffective (13).

On the other hand, stigma is a significant obstacle for seeking mental health services that can be assessed from the individual, family members and society point of view. Stigma also affects negatively on the quality of life of people with mental illness $(14,15)$. Therefore, beliefs and attitudes of child labor caregivers about mental health issues and first aid that can be provided, also their attitude towards mental stigma, can affect their motivation to learn first aid and seek professional help for these children. Since no study has been conducted in this field in Iran so far, the main purpose of this study is measuring the child labor caregivers' mental health literacy about first aid and their attitude towards the stigma of mental disorders. The results of this study can be used to improve the child labor caregivers' mental health literacy and can be a starting point for designing community-based interventions in order to reduce stigma of psychiatric disorders among child labor caregivers and improve early diagnosis and help treating cases and their complications.

\section{Methods}

This was a cross-sectional study. The statistical population were caregivers of under 18 years old working children who spent most of their time in low-level jobs at workplace or on the street without adult supervision covered by an NGO in the 17th district of Tehran. In this study a caregiver point to a person who is responsible for the child's affairs which mainly includes the child's mother. In cases when the child did not have a mother and another person was in charge of his responsibility (father, grandmother,...), this person was questioned as a caregiver.

Inclusion criteria included caregivers of all child labor under the age of 18 covered by the NGO, who willing to participate in the study. Exclusion criteria were the presence of a known psychiatric illness in the child or their caregiver or absence of a fixed caregiver. Sampling was done using convenience method and performed as census, therefore included all caregivers of child labor covered by the NGO.

The questionnaires used were the depression health literacy questionnaire, which had been previously translated and standardized by the authors of the present study (16). This questionnaire includes various areas such as recognizing the disorder, intent to seek help and perceived barriers, beliefs and intent to seek first aid, beliefs about interventions, beliefs about prevention, attitudes toward stigma and social isolation. In this study areas of beliefs and intent to seek first aid and attitudes toward stigma and social isolation were investigated.

In this questionnaire, vignette's psychiatric disorder is selected depending on the researcher intention. Due to the prevalence of depression in child labor (17), for this study a child with depressive symptoms was selected as vignette. The researcher attended the NGO and explained the research questionnaire then deliver them to the child caregivers. The questionnaires were completed by child labor caregivers with the guidance of the questioner (child caregivers in the organization). 
In cases when the caregiver was not literate enough to complete the questionnaire, the researcher helped participants to complete questionnaires.

\section{Data analysis}

Data analysis was performed using SPSS software. Quantity and percentage and mean and standard deviation were used to describe qualitative and quantitative variables respectively. Kolmogorov-Smirnov test was used to evaluate normal distribution of quantitative variables.

\section{Results}

Of the caregivers, 131 participants completed the questionnaires of which 2 questionnaires had been answered less than $80 \%$ of the questions and were deleted. Finally, 129 questionnaires were analyzed. Caregivers' mean age was $32.6( \pm 7)$ years with a minimum and maximum age of 19 and 57 years respectively. Among the participants 114 (99.1\%) persons were residents of district 18 and $1(0.9 \%)$ was resident of district 16 of Tehran.

Other demographic information about the participants is showed in Table 1.

Table 1

Characteristic of participants

\begin{tabular}{|llll|}
\hline \multirow{3}{*}{ Education } & & Frequency & Percent \\
& illiterate & 71 & 55.9 \\
\cline { 2 - 4 } & Under diploma & 44 & 34.6 \\
\cline { 2 - 4 } Marriage status & Diploma & 12 & 9.4 \\
\cline { 2 - 4 } & Married & 108 & 83.7 \\
\cline { 2 - 4 } Occupation & Divorced or Widowed & 11 & 8.5 \\
\cline { 2 - 4 } & Single & 10 & 7.8 \\
\cline { 2 - 4 } & Worker & 56 & 44.1 \\
& Housewife & 52 & 41 \\
\cline { 2 - 4 } & Vendor & 19 & 14.9 \\
\cline { 2 - 4 } & &
\end{tabular}

In answer to the question "How confident would you be in your ability to help vignette", the responses were 37 (30.3\%) sure, 42 (34.4\%) unsure and 43 (33.3\%) "I don't know".

Participants' answers to whether first aid items can be helpful are given in Table 2. 
Table 2

Participants ' belief about first aids items

\begin{tabular}{|c|c|c|c|c|}
\hline & $\begin{array}{l}\text { Helpful } \\
\mathrm{N}(\%)\end{array}$ & $\begin{array}{l}\text { No helpful } \\
\text { no harmful } \\
\mathrm{N}(\%)\end{array}$ & $\begin{array}{l}\text { I don't } \\
\text { know } \\
\mathrm{N}(\%)\end{array}$ & Harmful \\
\hline $\begin{array}{l}\text { Listen to (his/her) problems in an understanding } \\
\text { way }\end{array}$ & $121(94.5)$ & $6(4.7)$ & $1(0.8)$ & $0(0)$ \\
\hline $\begin{array}{l}\text { Make an appointment for (him/her) to see a GP or } \\
\text { counselor if necessary }\end{array}$ & $38(29.5)$ & $9(7)$ & $\begin{array}{l}80 \\
(62)\end{array}$ & $2(1.6)$ \\
\hline Ask (him/her) whether (he/she) is feeling suicidal & $3(2.3)$ & $0(0)$ & $\begin{array}{l}17 \\
(13.2)\end{array}$ & $\begin{array}{l}109 \\
(84.5)\end{array}$ \\
\hline Suggest (him/her) smoke cigarettes to relax & $0(0)$ & $0(0)$ & $0(0)$ & $\begin{array}{l}129 \\
(100)\end{array}$ \\
\hline Ignore (him/her) until (he/she) gets over it & $34(26.4)$ & $79(61.2)$ & $1(0.8)$ & $\begin{array}{l}15 \\
(11.6)\end{array}$ \\
\hline $\begin{array}{l}\text { Keep (him/her) busy to keep (his/her) mind off } \\
\text { problems }\end{array}$ & $59(46.5)$ & $62(48.8)$ & $2(1.6)$ & $4(3.1)$ \\
\hline $\begin{array}{l}\text { Encourage him/her to become more physically } \\
\text { active }\end{array}$ & $60(46.5)$ & $60(46.5)$ & $7(5.4)$ & $2(1.6)$ \\
\hline
\end{tabular}

Table 3

Participants` belief related to stigma

\begin{tabular}{|c|c|c|c|}
\hline & $\begin{array}{l}\text { Agree } \\
\mathrm{N}(\%)\end{array}$ & $\begin{array}{l}\text { No agree no } \\
\text { disagree } \\
\mathrm{N}(\%)\end{array}$ & $\begin{array}{l}\text { Disagree } \\
N(\%)\end{array}$ \\
\hline His/her problem is treatable & $74(57.4)$ & $54(41.9)$ & $1(0.8)$ \\
\hline His/her problem is not a real medical illness & $\begin{array}{l}32 \\
(24.8)\end{array}$ & $68(53.1)$ & $\begin{array}{l}28 \\
(21.9)\end{array}$ \\
\hline $\mathrm{He} /$ she is not dangerous to others & $\begin{array}{l}50 \\
(38.8)\end{array}$ & $75(58.1)$ & $4(3.1)$ \\
\hline $\begin{array}{l}\text { It is best to avoid him/her so that you don't develop this } \\
\text { problem yourself. }\end{array}$ & 11(8.6) & $65(50.8)$ & $\begin{array}{l}52 \\
(40.6)\end{array}$ \\
\hline $\begin{array}{l}\text { You would not tell anyone if you had a problem like } \\
\text { him/her }\end{array}$ & $\begin{array}{l}15 \\
(11.6)\end{array}$ & $74(57.4)$ & $40(31)$ \\
\hline
\end{tabular}

\section{Discussion}


The aim of this study was to investigate the child labor caregivers' beliefs and attitudes about first aid and stigma of mental health problems. Most people are often aware of their physical health problems while mental health problems are often overlooked. This issue along with the stigma about mental disorders prevents people from seeking early help for their mental health problems (10). They also often do not know how to properly support other persons around with mental problems (18). In order to improve this aspect of mental health literacy, Mental Health First Aid (MHFA) training courses were prepared and implemented. Its 5 main steps include assess risk of suicide or harm; listen non-judgmentally; give reassurance and information; encourage person to get appropriate professional help; encourage self-help strategies (10).

Mental health first aid emphasizes that people with mental health problems can be identified and supported similarly to physical health problems by community members who can play a useful primary role. On the other hand, due to the high prevalence of mental health problems, community members are more likely to encounter with someone experiencing a mental health crisis than a physical health crisis such as coronary artery event, so it will be important for them to know how to help their loved ones using first aid.

In this regard, the responsibility for caring of community members' mental health goes beyond specialized mental health services and even beyond health services in general (19). In line with above explanation, one of the first important questions in the field of first aid for mental health is "How confident would you be in your ability to help vignette". The findings of the present study showed that only $30 \%$ of caregivers were confident that they could help a child with a problem reported in Vignette. In comparison with this result, a study conducted in adults in Tehran showed that $6 \%$ were completely and $75 \%$ were somewhat confident in helping (12). In the Yoshioka study (20), 3\% of Japanese youth and in the Jorm study, $30 \%$ of Australian youth were completely confident (21).

Regarding the appropriate behavior for first aid, the majority of caregivers (94.5\%) believed that listening to the child with problem is helpful when in the study of Tehran, the majority (about 60\%) considered listening to vignette appropriate (12).

While according to studies, asking about suicidal ideation is one of the mental health first aid measures $(10,22)$, the majority of participants $(84.5 \%)$ believed that asking this question from a person with mental health problem would be detrimental.

That this belief can be due to the stigma associated with suicide and the avoidance of any reference to it, as well as the fear of possible encouragement to attempt suicide. Only $30 \%$ of participants believed that visiting a general practitioner or counselor was helpful that was almost similar to the findings of Tehran survey (12). This finding may be due to the lack of knowledge about the effectiveness of professional interventions for psychiatric disorders that in this case, providing the necessary trainings in order to increase the awareness and the ability to provide mental health first aid for the child labor caregivers can help to raise awareness in this area. 
A meta-analysis study showed that MHFA training programs could be a promising public health intervention to combat stigma and taboos for mental disorders and prevent suicide (6). Stigma is also one of the biggest barriers to receiving specialized services by people with psychiatric disorders who refuse to accept the disease and do not seek services from experts in this field (23).

Based on the findings of this study, $57 \%$ of caregivers believed that depression, like any other disorder can be treated, in Ghadirian study it was $88 \%$ in Tehran residents and in Sayarifard study it was $75 \%$ in students in Tehran University of Medical Sciences $(5,16)$. In the present study, similar to the findings of the Yeap study in Malaysia (24) about 25\% of caregivers believed that depressive disorder was not a real medical illness when it was $8.6 \%$ in the Reavley study in Australia (25).

This finding is important because first aid training, by correcting this wrong belief that depression is not a real illness, can affect their willingness to seek care and receive related assistance (26).

In this study $39 \%$ of participants agreed that the vignette was not dangerous for others, which showed a more negative attitude compared to similar studies $(5,16,25)$.

More than half of the participants responded negatively about staying away from the person with depressive disorder and not talking about this problem with others. This negative attitude can affect the request for help, initial diagnostic and care measures as other studies that have shown the relationship between stigma and help-seeking (27). Findings of Jung study has indicated the need to strengthen social support to promote a positive attitude towards psychological issues.

Mental health education can be useful for people at risk for mental illness and for families who are likely to influence on helping attitudes of people with mental illness (28). On the other hand, Yoshioka's study showed that perceived stigma is significantly associated with various biogenetic, psychosocial and personality factors (29).

Other studies have reported that despite many anti-stigma programs and extensive researches in this area, it is still difficult to find effective ways to combat stigma against mental illness in the population and to determine community-based interventions, more research is needed in this area (30-32).

The present study was conducted only on a group of caregivers of child labor covered by an NGO in Tehran and is not generalizable to the whole community, however, due to the fact that no study has been conducted on the mental health literacy in this target group in Iran so far, conducting this study is a strength to start further studies in this target group in order to improve their mental health and ultimately improve the mental health of child labor who are from disadvantaged groups in society.

\section{Conclusion}

According to the findings of this study, the literacy of child labor caregivers about mental health first aid is not enough and there is need to conduct interventions including providing the necessary trainings in this area. 
There is also a need for educational and, of course, community-based programs to reduce the stigma about mental health disorders including depression.

\section{Declarations}

\section{Ethics approval and consent to participate}

The Ethics Committee of Tehran University of Medical Sciences and Health Services approved the study (IR.TUMS.VCR.REC.1397.398). The verbal informed consent was given from participants. On the other hand, cooperation in answering the interview questions showed their satisfaction for participating in the study.

\section{Consent for publication}

Not applicable

\section{Availability of data and materials}

The datasets during and/or analyzed during the current study available from the corresponding author on reasonable request.

\section{Competing interests}

The authors declare that they have no competing interests.

\section{Funding}

This research has been supported by Tehran University of Medical Sciences and health Services grant (97-01-62-38157). The funding body had no role in the design of the study and collection, analysis, and interpretation of data and in writing the manuscript.

\section{Authors' contributions}

AS and LGh, Designed the study. LGh collected the data. AS analyzed the data and drafted the manuscript. Both authors read, correct and approved the final manuscript.

\section{Acknowledgments}

Authors acknowledge all the participants in this study and support from Tehran University of Medical Sciences, Tehran, Iran.

\section{References}

1. Tiwari RR, Saha A, Parikh JR, Saiyed HN. Injuries and injury care among child labourers in gem polishing industries in Jaipur, India. Journal of occupational health. 2004;46(3):216-9. 
2. Khakshour A, Ajilian Abbasi M, Sayedi SJ, Saeidi M, Khodaee GH. Child labor facts in the worldwide: A review article. International Journal of Pediatrics. 2015;3(1.2):467-73.

3. O'Donnell O, Van Doorslaer E, Rosati FC. Child labour and health: Evidence and research issues. Understanding Children's Work Programme Working Paper. 2002.

4. Al-Gamal E, Hamdan-Mansour AM, Matrouk R, Nawaiseh MA. The psychosocial impact of child labour in Jordan: a national study. International Journal of Psychology. 2013;48(6):1156-64.

5. Ghadirian L, Sayarifard A. Depression literacy in urban and suburban residents of Tehran, the Capital of Iran; Recognition, help seeking and stigmatizing attitude and the predicting factors. International journal of preventive medicine. 2019;10.

6. Hadlaczky G, Hökby S, Mkrtchian A, Carli V, Wasserman D. Mental Health First Aid is an effective public health intervention for improving knowledge, attitudes, and behaviour: A meta-analysis. International Review of Psychiatry. 2014;26(4):467-75.

7. Jorm AF, Kitchener BA, Fischer J-A, Cvetkovski S. Mental health first aid training by e-learning: a randomized controlled trial. Australian and New Zealand Journal of Psychiatry. 2010;44(12):107281.

8. Jorm AF, Kitchener BA, Mugford SK. Experiences in applying skills learned in a Mental Health First Aid training course: a qualitative study of participants' stories. BMC psychiatry. 2005;5(1):43.

9. Jorm AF, Kitchener BA, O'Kearney R, Dear KB. Mental health first aid training of the public in a rural area: a cluster randomized trial [ISRCTN53887541]. BMC psychiatry. 2004;4(1):33.

10. Kitchener BA, Jorm AF. Mental health first aid training: review of evaluation studies. Australian \& New Zealand Journal of Psychiatry. 2006;40(1):6-8.

11. Lynch DM, Gennat HC, Celenza T, Jacobs IG, O'Brien D, Jelinek GA. Community senior first aid training in Western Australia: its extent and effect on knowledge and skills. Australian and New Zealand journal of public health. 2006;30(2):147-50.

12. Sayarifard A, Ghadirian L. How are the beliefs about mental health first aid among adults? Asian journal of psychiatry. 2018;35:91.

13. Organization WH. Psychological first aid: guide for field workers: World Health Organization; 2011.

14. Dalky HF. Mental illness stigma reduction interventions: Review of intervention trials. Western journal of nursing research. 2012;34(4):520-47.

15. Talbot R, Malas N. Addressing mental health stigma: A pilot educational video intervention for caregivers to facilitate psychiatric consultation in inpatient pediatric care settings. Clinical child psychology and psychiatry. 2019;24(4):754-66.

16. Sayarifard A, Ghadirian L, Mohit A, Eftekhar M, Badpa M, Rajabi F. Assessing mental health literacy: What medical sciences students' know about depression. Medical journal of the Islamic Republic of Iran. 2015;29:161.

17. Ahmad Khaniha HR, Turkman Nejad S, Hussaini Moghaddam MM. Epidemiology of Depression and Sexual Abuse among Street Children. Iranian Journal of Psychiatry and Clinical Psychology. 
2002;8(1):14-20.

18. Jorm AF, Blewitt KA, Griffiths KM, Kitchener BA, Parslow RA. Mental health first aid responses of the public: results from an Australian national survey. BMC psychiatry. 2005;5(1):9.

19. Kitchener BA, Jorm AF. Mental Health First Aid: an international programme for early intervention. Early Intervention in Psychiatry. 2008;2(1):55-61.

20. Yoshioka K, Reavley NJ, Rossetto A, Jorm AF. Beliefs about first aid for mental disorders: results from a mental health literacy survey of Japanese high school students. International Journal of Culture and Mental Health. 2015;8(2):223-30.

21. Jorm AF, Wright A, Morgan AJ. Beliefs about appropriate first aid for young people with mental disorders: findings from an Australian national survey of youth and parents. Early Intervention in Psychiatry. 2007;1(1):61-70.

22. Jorm AF, Morgan AJ, Wright A. First aid strategies that are helpful to young people developing a mental disorder: beliefs of health professionals compared to young people and parents. BMC psychiatry. 2008;8(1):42.

23. Campbell RD, Mowbray O. The stigma of depression: Black American experiences. Journal of Ethnic \& Cultural Diversity in Social Work. 2016;25(4):253-69.

24. Yeap R, Low W. Mental health knowledge, attitude and help-seeking tendency: a Malaysian context. Singapore Med J. 2009;50(12):1169-76.

25. Reavley NJ, Jorm AF. Young people's stigmatizing attitudes towards people with mental disorders: findings from an Australian national survey. Australian and New Zealand Journal of Psychiatry. 2011;45(12):1033-9.

26. Lopez V, Sanchez K, Killian MO, Eghaneyan BH. Depression screening and education: an examination of mental health literacy and stigma in a sample of Hispanic women. BMC public health. 2018;18(1):646.

27. Ibrahim N, Amit N, Shahar S, Wee L-H, Ismail R, Khairuddin R, et al. Do depression literacy, mental illness beliefs and stigma influence mental health help-seeking attitude? A cross-sectional study of secondary school and university students from B40 households in Malaysia. BMC public health. 2019;19(4):544.

28. Jung H, von Sternberg K, Davis K. The impact of mental health literacy, stigma, and social support on attitudes toward mental health help-seeking. International Journal of Mental Health Promotion. 2017;19(5):252-67.

29. Yoshioka K, Reavley NJ, Rossetto A, Nakane Y. Associations between beliefs about the causes of mental disorders and stigmatizing attitudes: Results of a mental health literacy and stigma survey of the Japanese public. International Journal of Mental Health. 2016;45(3):183-92.

30. Corrigan PW, Morris SB, Michaels PJ, Rafacz JD, Rüsch N. Challenging the public stigma of mental illness: a meta-analysis of outcome studies. Psychiatric services. 2012;63(10):963-73.

31. Reavley NJ, Jorm AF. Public recognition of mental disorders and beliefs about treatment: changes in Australia over 16 years. The British Journal of Psychiatry. 2012;200(5):419-25. 
32. Svensson B, Hansson L. How mental health literacy and experience of mental illness relate to stigmatizing attitudes and social distance towards people with depression or psychosis: A crosssectional study. Nordic journal of psychiatry. 2016;70(4):309-13. 